\title{
Rock-magnetic changes with reduction diagenesis in Japan Sea sediments and preservation of geomagnetic secular variation in inclination during the last 30,000 years
}

\author{
Toshitsugu Yamazaki ${ }^{1}$, Abdelaziz L. Abdeldayem ${ }^{2}$, and Ken Ikehara ${ }^{1}$ \\ ${ }^{1}$ Institute for Marine Resources and Environment, Geological Survey of Japan, AIST, Japan \\ ${ }^{2}$ Faculty of Science, Tanta University, Egypt
}

(Received February 4, 2003; Revised June 16, 2003; Accepted June 21, 2003)

\begin{abstract}
A rock-magnetic and paleomagnetic study was conducted on a sediment core of about $4.4 \mathrm{~m}$ long taken from the northeastern part of the Japan Sea. The core covers the last about $30 \mathrm{kyrs}$, which was dated by nineteen radiocarbon $\left({ }^{14} \mathrm{C}\right)$ ages. Remanent magnetization is carried dominantly by magnetite. Reductive dissolution of magnetic minerals occurs between 1.2 and $1.6 \mathrm{~m}$ in depth (about 5-8 ka in age). A rapid downcore decrease of anhysteretic remanent magnetization (ARM) begins at the shallowest depth. Saturation isothermal remanent magnetization (SIRM) follows, and a decrease of magnetic susceptibility $(k)$ takes place at the deepest. Within this zone, coercivity of natural remanent magnetization (NRM) and the ratios of ARM to $k$ and SIRM to $k$ also decreases with depth. These observations indicate that finer magnetic grains were lost earlier than larger grains. A decrease of $\mathrm{S}$ ratios, wasp-waisted hysteresis curves, and a deviation from a mixing trend of single-domain and multi-domain grains in a Day plot occur as the dissolution proceeds, which suggests that high coercivity minerals like hematite are more resistive to dissolution than low coercivity minerals like magnetite. The start of the dissolution at $1.2 \mathrm{~m}$ in depth is synchronous with increases in organic-carbon and total-sulfur contents, but the horizon does not coincide with the present Fe-redox boundary at about $0.02 \mathrm{~m}$ below the sediment-water interface. From low-temperature magnetometry, it is estimated that magnetites with maghemite skin are reduced to pure magnetites prior to dissolution. There is no evidence for precipitation of secondary magnetic phases and acquisition of chemical remanent magnetization (CRM). Neither pyrrhotite nor greigite was detected. Information of paleomagnetic directions have survived the reductive dissolution. Inclination variations of this core resembles closely to the secular variation records available around Japan. Well-dated records older than 10 ka are still very rare, and hence our new record could be useful for establishing regional secular variations.
\end{abstract}

Key words: Rock magnetism, reduction diagenesis, dissolution, secular variation, inclination, Japan Sea.

\section{Introduction}

Recently rock-magnetic proxies have been widely used for paleoenvironmental and paleoclimatological studies (e.g., Maher and Thompson, 1999). The Japan Sea is a semienclosed marginal basin located in the eastern margin of the Asian continent (Fig. 1). It has been known that sediments in the Japan Sea are a sensitive recorder of paleoclimate changes under strong influences of glacio-eustatic sea-level changes and the Asian monsoon, and the sediments have attracted a special interest of researchers who aim to reconstruct past climatic changes with high resolution (e.g. Tada et al., 1999). However, little rock-magnetic approach has been done for Japan Sea sediments since the study on magnetic mineralogy by Kobayashi and Nomura (1972). Vigliotti (1997) documented variations of magnetic properties with glacial-interglacial changes using the samples of Ocean Drilling Program (ODP) Leg 127, but this work remained a preliminary stage: only a few samples were taken for each glacial or interglacial period. To interpret magnetic properties in terms of paleoclimate, it is necessary

Copy right(C) The Society of Geomagnetism and Earth, Planetary and Space Sciences (SGEPSS); The Seismological Society of Japan; The Volcanological Society of Japan; The Geodetic Society of Japan; The Japanese Society for Planetary Sciences. to separate magnetic-property changes originated by sources and transport processes of magnetic minerals from changes caused by in situ alteration. We thus consider it is first necessary to understand changes of magnetic properties associated with reduction diagenesis. Diagenetic dissolution of magnetic minerals has often been documented in continental margin sediments (e.g., Karlin, 1990; Bloemendal et al., 1993), and this may occur also in Japan Sea sediments.

High-resolution paleomagnetic records are required to study, for example, detailed behavior of the geomagnetic field during a polarity transition. For this purpose, it is necessary to use sediments with very high sedimentation rates. However, such sediments are usually under high biological productivity regions along continental margins accompanying large supply of organic matter, and hence in a strongly reduced environment. These sediments have been thought to be unsuitable for paleomagnetic studies because they are geochemically active and dissolution and secondary precipitation of magnetic minerals can occur. Sediment drifts are exceptions, which are often in a relatively oxic condition despite rapid sedimentation, and high-quality polaritytransition records were reported from sediment drifts in the North Atlantic (Channell and Lehman, 1997). However, dis- 


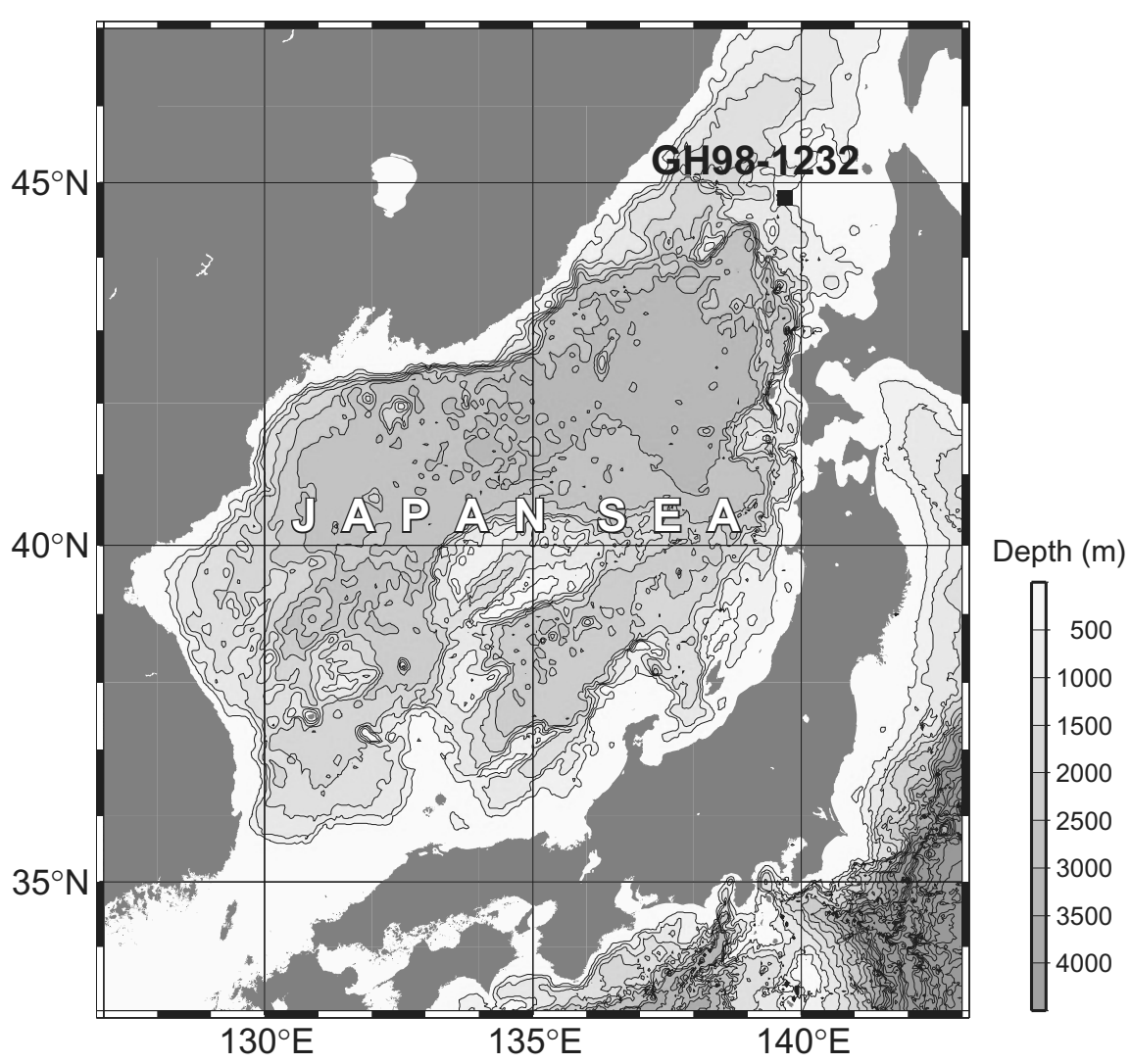

Fig. 1. Location of Core GH98-1232. Bathymetric contours are at $500 \mathrm{~m}$ intervals.
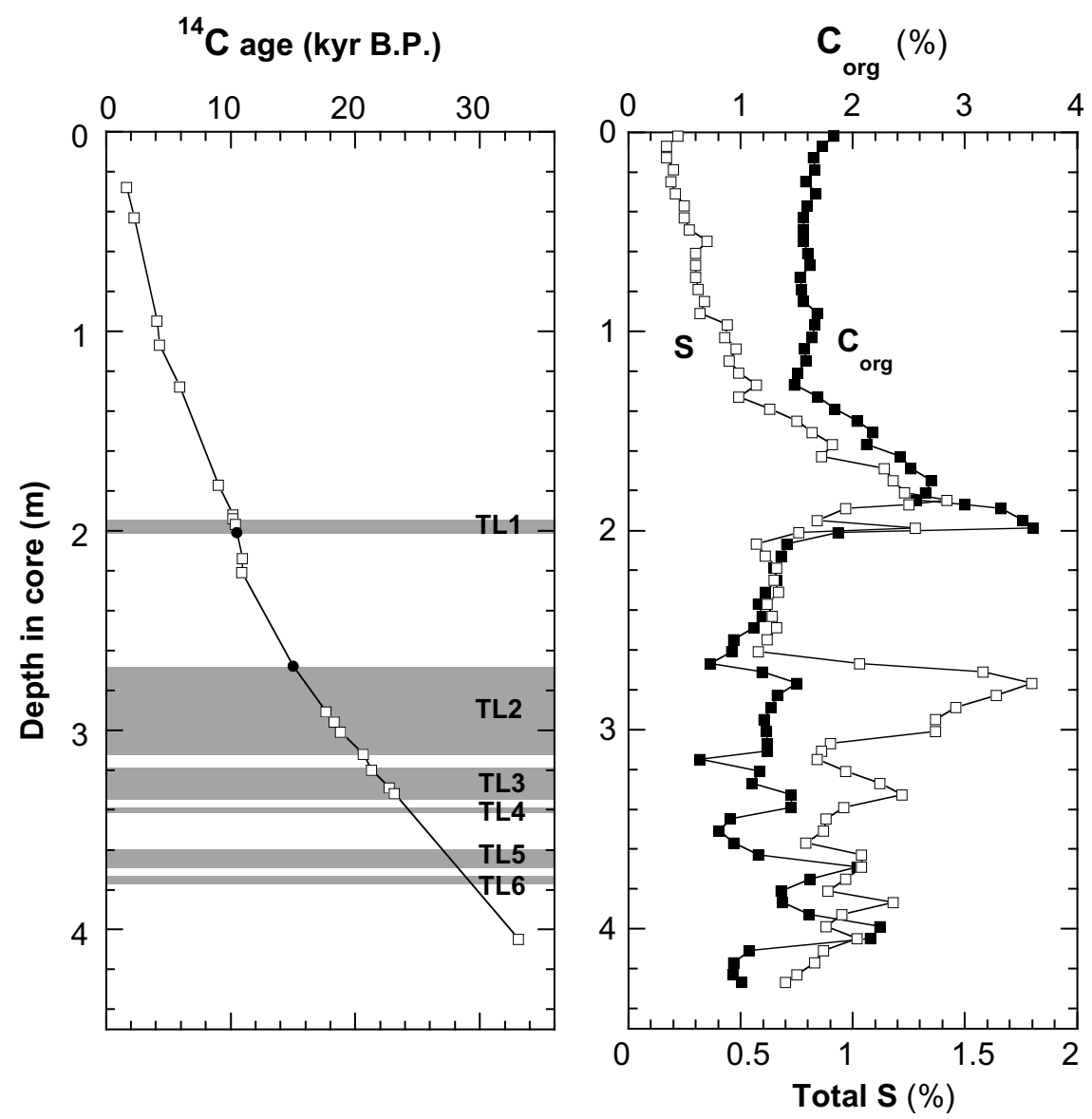

Fig. 2. (Left) Age-depth curve of Core GH98-1232 (Itaki and Ikehara, 2003). Shaded zones indicate thin-laminated dark layers (TL layers). Open squares are AMS ${ }^{14} \mathrm{C}$ ages (conventional age), and solid circles are control points based on ages of TL-1 and TL-2 layers. (Right) Organic-carbon (solid circles) and total-sulfur (open squares) contents (Terashima et al., 1999). 
tribution of sediment drifts is geographically limited. It is thus inevitable for paleomagnetists to utilize anoxic sediments for global site distribution of paleomagnetic records, as a polarity transition record of Yamazaki and Oda (2001), and it is required to understand rock-magnetic processes during reduction diagenesis in detail.

In this paper, we document variations of magnetic properties, in particular dissolution of magnetites, associated with reduction diagenesis using an anoxic sediment core taken from the Japan Sea. We discuss preservation of paleomagnetic secular variations in inclination during the last $30 \mathrm{kyrs}$ in the sediment core.

\section{Geological Setting and Core Sample}

The Japan Sea has an average water depth of about $1350 \mathrm{~m}$, and the maximum reaches approximately $3700 \mathrm{~m}$ (Fig. 1). The Japan Sea is connected with other marginal seas and the Pacific ocean through four shallow straits less than $130 \mathrm{~m}$ deep. Mainly because of the shallowness of the straits, drastic changes of oceanographic conditions occurred in the basin in association with paleoclimatic changes (e.g., Oba et al., 1991). Late Quaternary sediments of the Japan Sea are characterized by alternations of dark and light layers (Tada et al., 1992), which extends basinwide except for the areas shallower than about $500 \mathrm{~m}$ in depth (Ikehara et al., 1994). The dark layers are laminated in most cases, called TL layers, whereas the light layers are homogeneous to bioturbed. TL layers above the Aso-4 ash layer ( $88 \mathrm{ka}$ ) were numbered from TL-1 to TL-21 (Tada et al., 1999). The TL1 layer is probably correlative to the Younger Dryas event from its age, $10.5{ }^{14} \mathrm{C}$ kyr BP (Oba et al., 1995; Ikehara et al., 1996), and the age of TL-2, from 15 to $23{ }^{14} \mathrm{C} \mathrm{kyr} \mathrm{BP}$, implies that it was formed during a falling stage of sea level in the last glacial maximum.

A gravity core GH98-1232 of about $4.4 \mathrm{~m}$ in length was obtained in the northeastern part of the Japan Sea at $44^{\circ} 48.09^{\prime} \mathrm{N}, 139^{\circ} 41.97^{\prime} \mathrm{E}$. Water depth of the coring site is $838 \mathrm{~m}$. The core is composed of homogeneous, burrowed or thinly laminated silty clay of olive black to olive gray in color. An oxidized layer of only about $0.02 \mathrm{~m}$ was observed at the top of the core, which indicates that present Fe-redox boundary occurs very close to the sediment-water interface. Six TL layers were recognized in this core (Fig. 2). An age-depth relationship of this core was established by nineteen AMS radiocarbon $\left({ }^{14} \mathrm{C}\right)$ ages of planktonic foraminifers (Itaki and Ikehara, 2003), and the ages of the bottom of TL-1 layer and the top of TL-2 layer, 10.5 and $15{ }^{14} \mathrm{C}$ kyr BP, respectively (Fig. 2). Conventional ${ }^{14} \mathrm{C}$ ages (not converted to calendar ages) are used in this study because the magnitude of the carbon reservoir effect is not known in the Japan Sea. The sedimentation rate decreases with depth in core: about $20 \mathrm{~cm} / \mathrm{kyr}$ in average for the top $1 \mathrm{~m}$ of the core, and about $7 \mathrm{~cm} / \mathrm{kyr}$ for the bottom $1 \mathrm{~m}$. This core has relatively high organic-carbon and total-sulfur contents (Terashima et al., 1999) (Fig. 2), indicating a reduced condition. Total sulfur content is significantly higher in both TL-1 and TL-2 layers, whereas an increase of organic carbon content in TL-2 layer is small. Downcore increase of both organic-carbon and total-sulfur contents toward TL-1 layer begins at about $1.3 \mathrm{~m}$ in depth.

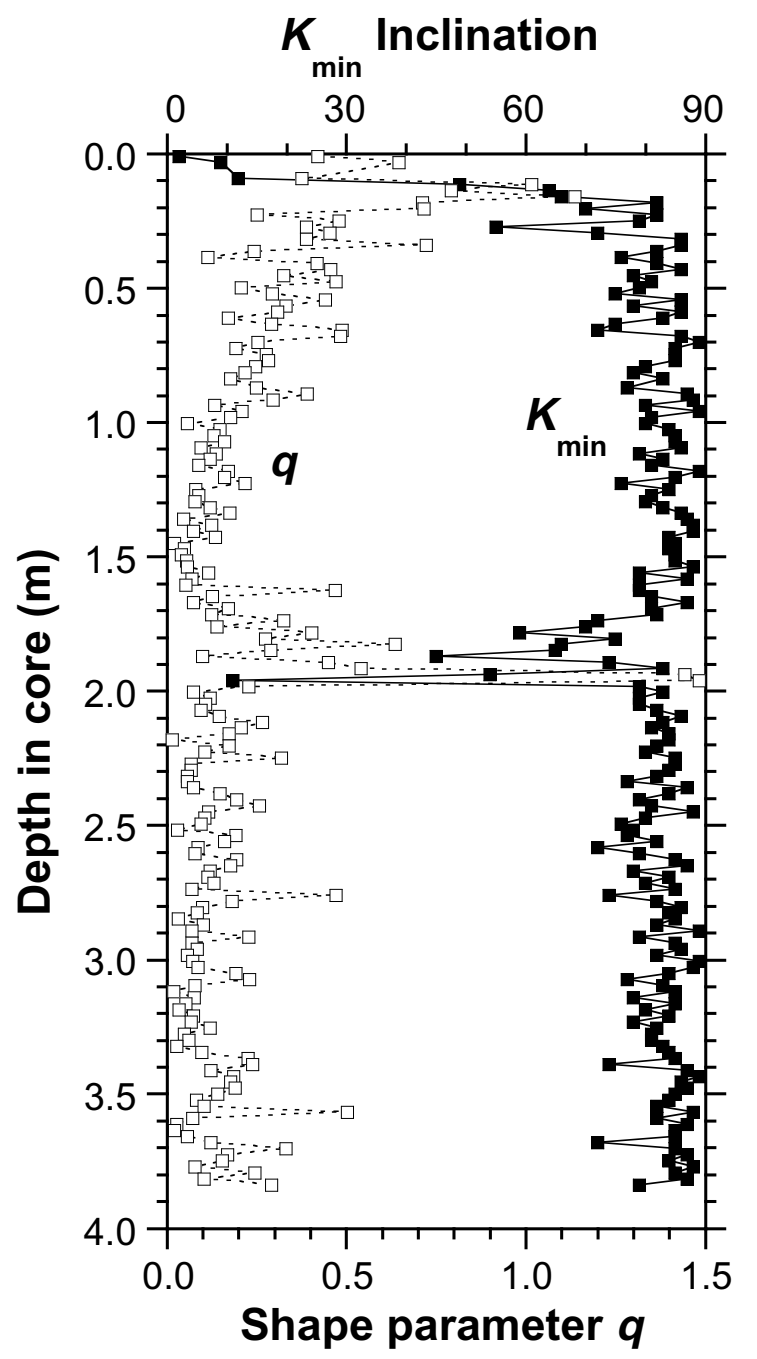

Fig. 3. Down-core variations of $K_{\min }$ inclination (solid squares) and shape parameter $q$ (open squares) of anisotropy of magnetic susceptibility (AMS).

Samples for paleomagnetic and rock-magnetic measurements were taken onboard soon after the core recovery in 1998. A total of 168 discrete samples were obtained consecutively from half-split sections of the core using plastic cubes of $7 \mathrm{~cm}^{3}$.

\section{Method}

Anisotropy of magnetic susceptibility (AMS) was first measured on all discrete samples using a Kappabridge KLY$3 \mathrm{~S}$ susceptometer. AMS is represented by a symmetrical second-rank tensor, which is described by a triaxial ellipsoid with the principal eigenvectors, $K_{\max }>K_{\text {int }}>K_{\min }$, corresponding to the maximum, intermediate, and minimum susceptibility axes, respectively. The mean susceptibility $(k)$ is defined as the mean of $K_{\max }, K_{\text {int }}$, and $K_{\min }$. Next, natural remanent magnetization (NRM) measurement with stepwise alternating-field (AF) demagnetization was performed on all samples using a cryogenic magnetometer system with an inline static AF demagnetizer ( $2 \mathrm{G}$ Enterprises model 760R). Then, anhysteretic remanent magnetization (ARM) was given on every other samples by superimposing a DC biasing field of $0.1 \mathrm{mT}$ on a smoothly decreasing AF with 

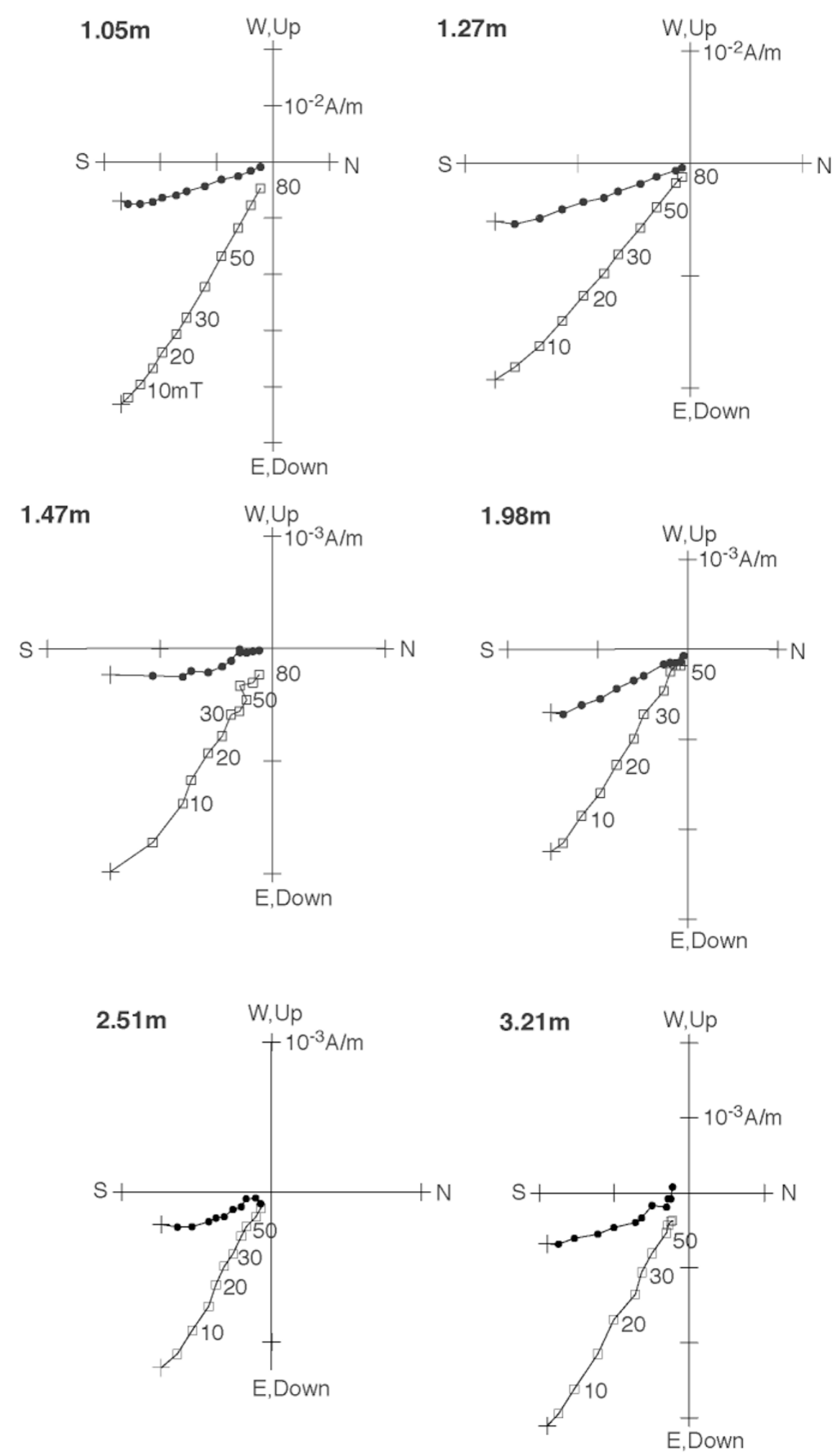

Fig. 4. Examples of stepwise alternating-field (AF) demagnetization data. Open circles are projection of vector end-points on the vertical plane, and solids are on the horizontal plane. The core is not oriented azimuthally.

a peak field of $80 \mathrm{mT}$. The intensity of ARM was normalized by the strength of the DC field, and ARM susceptibility $\left(k_{\mathrm{ARM}}\right)$ was obtained. Finally, isothermal remanent magnetization (IRM) acquisition experiments were performed after demagnetizing the ARM by AF of $80 \mathrm{mT}$. An IRM of $2.5 \mathrm{~T}$ was given with a pulse magnetizer ( $2 \mathrm{G}$ model 660$)$, which was regarded as saturated (SIRM). Then, IRMs of $0.1 \mathrm{~T}$ and
$0.3 \mathrm{~T}$ were successively imparted in the direction opposite to SIRM. The IRMs were measured using a spinner magnetometer (Natsuhara-Giken SMM-85). S ratios $\left(\mathrm{S}_{-0.1 \mathrm{~T}}\right.$ and $\mathrm{S}_{-0.3 \mathrm{~T}}$ ) and HIRM (high-coercivity fraction of IRM) were calculated according to the definition of Bloemendal et al. (1992), and MIRM (middle-coercivity fraction of IRM) was calculated likewise: 

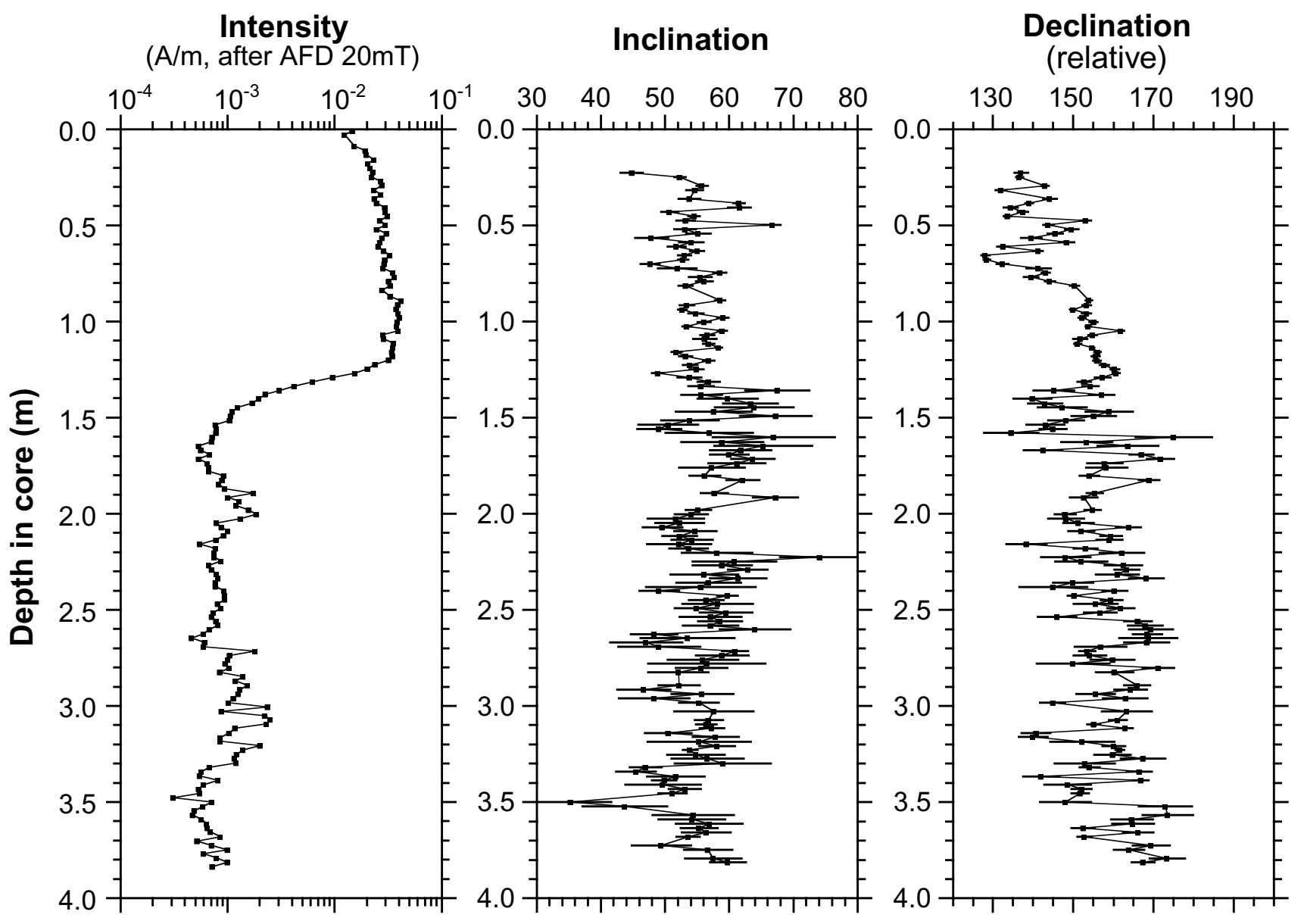

Fig. 5. Intensity (left), inclination (center), and relative declination (right) of natural remanent magnetization of Core GH98-1232 after AF demagnetization of $20 \mathrm{mT}$. Directions were determined by the principal component analysis (PCA). Error bars are values of maximum angular deviation (MAD) on PCA. The core is not oriented azimuthally.

$$
\begin{aligned}
\mathrm{S}_{-0.1 \mathrm{~T}} & =\left(1-\mathrm{IRM}_{-0.1 \mathrm{~T}} / \mathrm{IRM}_{2.5 \mathrm{~T}}\right) / 2 \\
\mathrm{~S}_{-0.3 \mathrm{~T}} & =\left(1-\mathrm{IRM}_{-0.3 \mathrm{~T}} / \mathrm{IRM}_{2.5 \mathrm{~T}}\right) / 2 \\
\mathrm{HIRM} & =\left(\mathrm{IRM}_{2.5 \mathrm{~T}}+\mathrm{IRM}_{-0.3 \mathrm{~T}}\right) / 2 \\
\mathrm{MIRM} & =\left(\mathrm{IRM}_{2.5 \mathrm{~T}}+\mathrm{IRM}_{-0.1 \mathrm{~T}}\right) / 2-\mathrm{HIRM}
\end{aligned}
$$

Magnetic domain state and mineralogy were examined on selected samples by magnetic hysteresis measurements and low-temperature magnetometry. The samples were selected mainly from 0.7 to $2.2 \mathrm{~m}$ in depth of the core where large changes were observed in magnetic concentration proxies shown later, but some samples from shallower and deeper than this interval were also measured. The samples were dried just before the measurements. Magnetic hysteresis curves were measured on 47 samples using an alternating-force gradient magnetometer (Princeton Measurements MicroMag 2900) of Kyoto University. Lowtemperature magnetometry was performed on 21 samples with a low-temperature SQUID susceptometer (Quantum Design MPMS-XL5). First, an IRM of $2.5 \mathrm{~T}$ was imparted to a sample at $300 \mathrm{~K}$, and magnetization changes with temperature were measured by cycling the temperature between $300 \mathrm{~K}$ and $6 \mathrm{~K}$ in a nearly zero field. Next, an IRM of $2.5 \mathrm{~T}$ was given to the sample after having been cooled down to
$6 \mathrm{~K}$ in a zero field, and thermal demagnetization of the IRM up to $300 \mathrm{~K}$ was measured.

\section{Results \\ 4.1 AMS and NRM}

We evaluated if any disturbance of depositional fabric occurs based on inclinations of $K_{\min }$ and the shape parameter $q$. The shape parameter $q$ is defined as

$$
q=\left(K_{\max }-K_{\text {int }}\right) /\left[\left(K_{\max }+K_{\text {int }}\right) / 2-K_{\min }\right]
$$

A foliated ellipsoid with $q<0.67$ and $K_{\min }$ directions lying within $25^{\circ}$ of the vertical was considered to be indicative of primary sedimentary fabric (Tarling and Hrouda, 1993). It was revealed that primary sedimentary fabric is preserved in the most part of the sediment core (Fig. 3). Exceptions are within $0.3 \mathrm{~m}$ from the top of the core and an interval between 1.8 and $2.0 \mathrm{~m}$. The former is most probably due to physical disturbance during coring. The latter corresponds to the TL1 layer, but the cause of the loss of primary fabric there is unclear.

Stepwise AF demagnetization shows that remanent magnetization of most samples consists of single component except for the first few demagnetization steps up to $10 \mathrm{mT}$ in general (Fig. 4). Directions of NRM were determined by applying the principal component analysis (PCA) (Kirschvink, 


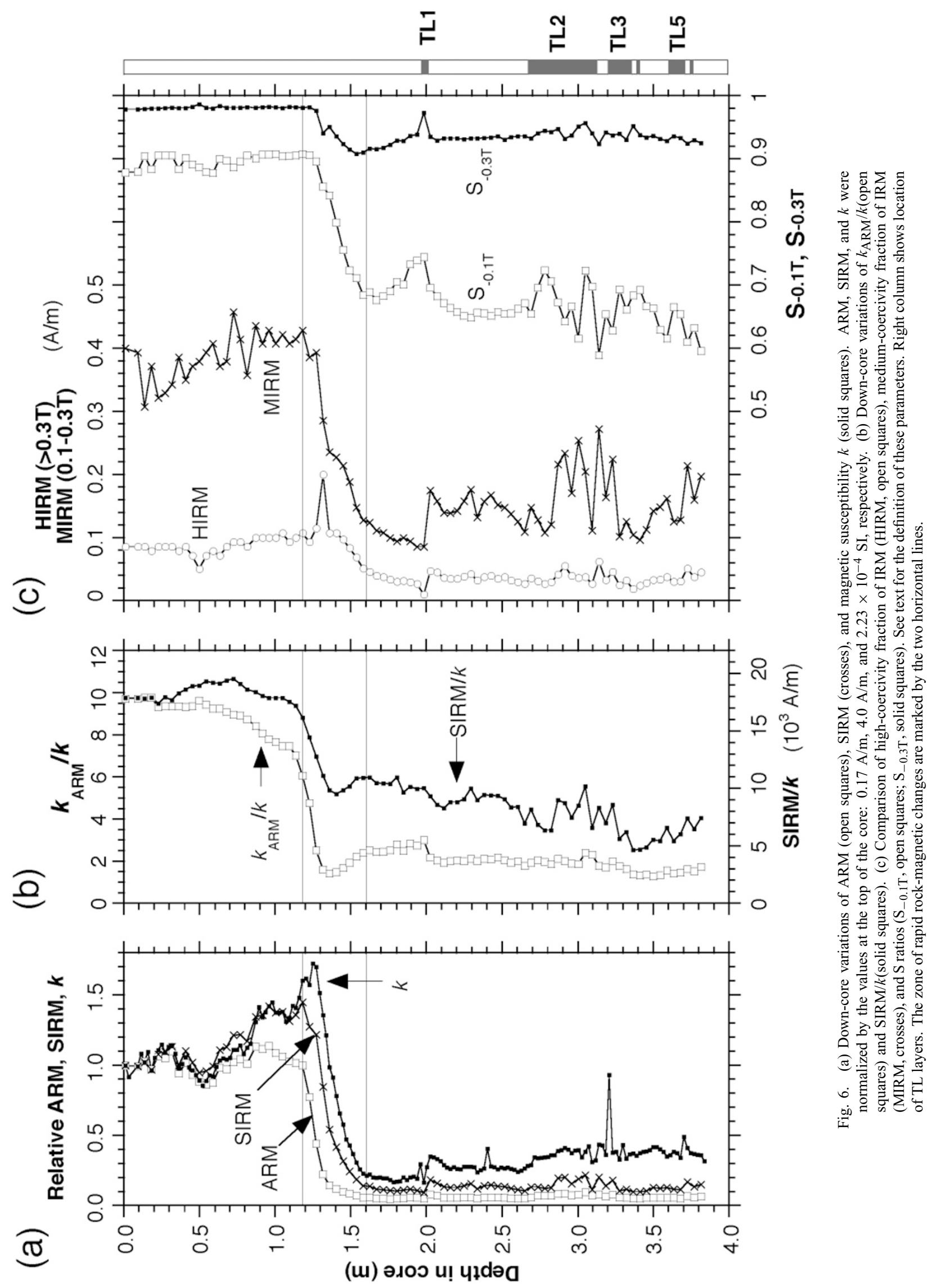


1980). Down-core variations of NRM direction and intensity are shown in Fig. 5. Small number of samples have maximum angular deviations (MADs) of larger than $10^{\circ}$, and such samples were excluded from the directional data. The samples which did not show primary fabric were also discarded. The gradual declination changes are due mainly to core-twisting. Declinations are not used here for studying secular variations because it is difficult to correct for the core-twisting. We consider inclinations were not affected by the twisting because no abrupt change was observed in declination. Remanent intensities are an order of $10^{-2} \mathrm{~A} / \mathrm{m}$ in the upper part of the core, and rapidly decrease between 1.2 and $1.6 \mathrm{~m}$ in depth. They are an order of $10^{-3} \mathrm{~A} / \mathrm{m}$ below $1.6 \mathrm{~m}$. Coercivity of NRM also decreases with the intensity decrease (Fig. 4). MADs range from $1^{\circ}$ to $3^{\circ}$ above the zone of intensity decrease, whereas they are about $5^{\circ}$ below it in general.

\section{2 $k$, ARM, and IRM}

Mean magnetic susceptibility $(k)$, ARM, and SIRM rapidly decrease between 1.2 and $1.6 \mathrm{~m}$ in depth (Fig. 6(a)), which represents a significant decrease in the concentration of magnetic minerals. Among the three parameters, the decrease of ARM begins at the shallowest depth. SIRM is the next, and the decrease of $k$ occurs at the deepest. Alternatively, they could be interpreted that ARM and SIRM begin to decrease at the same horizon, but the decay of SIRM is slow at first. Above $1.3 \mathrm{~m}, k$ shows a downcore increasing trend which starts from about $0.6 \mathrm{~m}$. Magnetic grain-size proxies, $k_{\mathrm{ARM}} / k$ and $\mathrm{SIRM} / k$, indicate rapid downward grain-size increase between 1.15 and $1.4 \mathrm{~m}$ (Fig. 6(b)). These observations indicate that finer magnetic grains were lost earlier than larger grains, and the average magnetic grain size of the sediments above the zone of rapid concentration decrease is smaller than that below it. Above the zone of the rapid grain-size increase, a gradual downcore increase seems to occur below about $0.7 \mathrm{~m}$, which is indicated by a decreasing trend in $k_{\mathrm{ARM}} / k$. S ratios, $\mathrm{S}_{-0.1 \mathrm{~T}}$ and $\mathrm{S}_{-0.3 \mathrm{~T}}$ (Fig. 6(c)), also decrease within the decreasing zone of magnetic concentration. $\mathrm{S}_{-0.3 \mathrm{~T}}$ is as high as 0.98 above $1.3 \mathrm{~m}$, which indicates the dominance of low-coercivity magnetic minerals like magnetite. It ranges from 0.92 to 0.94 below $1.6 \mathrm{~m}$, where magnetization is still carried dominantly by low-coercivity minerals, but relative abundance of highcoercivity minerals like hematite is larger than the shallower part. HIRM and MIRM also decrease simultaneously with SIRM (Fig. 6(c)). These observations indicate concentrations of all coercivity fractions decrease within the zone, and loss of higher coercivity fractions is relatively small. Gradual downcore increases in $k_{\mathrm{ARM}} / k$ and SIRM/ $k$ between 1.35 and $1.6 \mathrm{~m}$ accompany large changes in mineral composition as indicated by $\mathrm{S}$ ratios, and hence may not reflect grain-size variations.

A stepwise downward increase in magnetic concentration, both in low- and high-coercivity fractions, and small highs in $\mathrm{S}$ ratios were observed at $2.0 \mathrm{~m}$ in depth, which corresponds to the TL-1 layer. Also a small change in magnetic grain size is estimated there from $k_{\mathrm{ARM}} / k$. Some fluctuations in magnetic concentration proxies and $\mathrm{S}$ ratios are associated with TL-2 and other TL layers below.
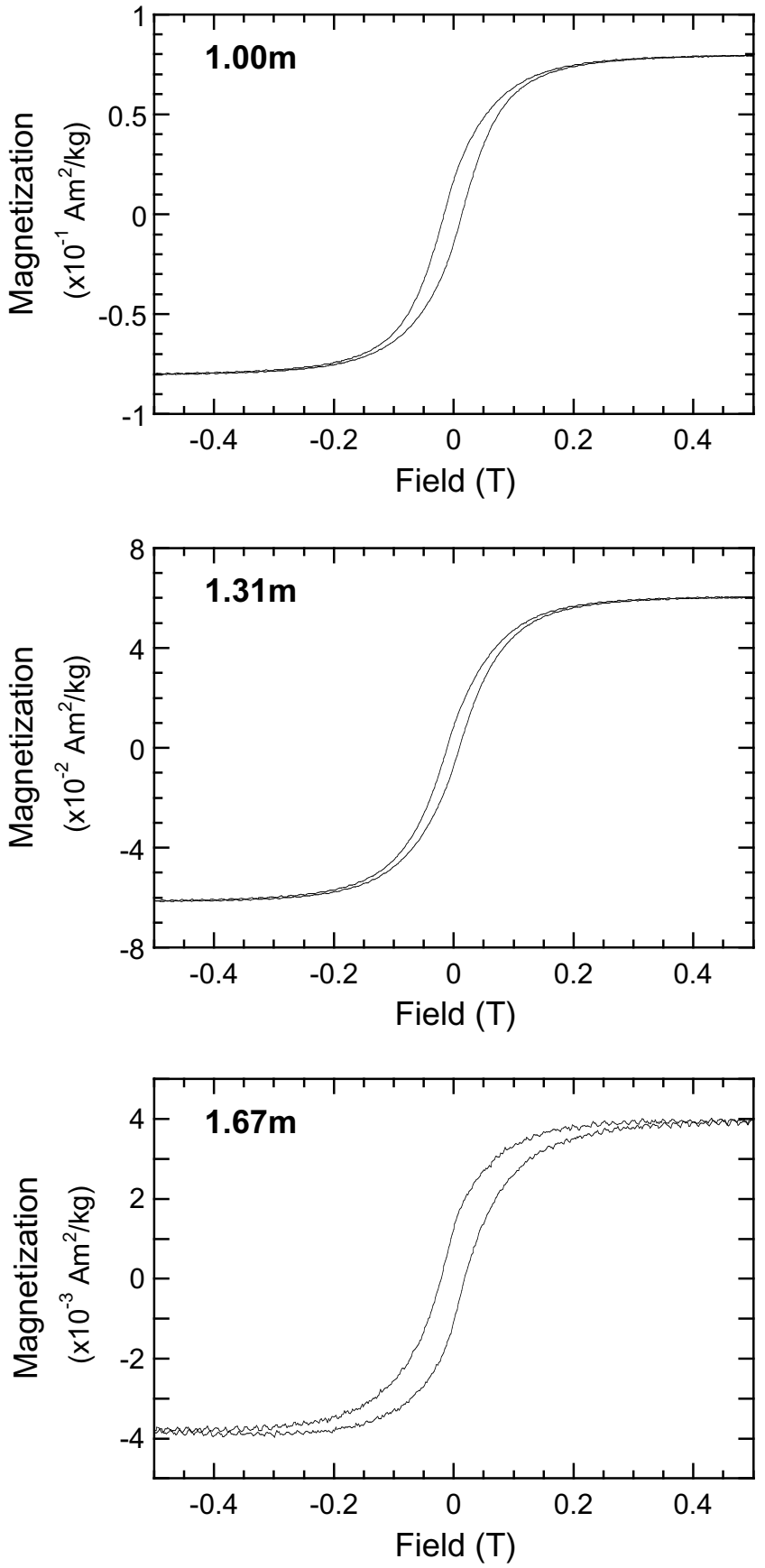

Fig. 7. Magnetic hysteresis curves after correcting for paramagnetic component. The examples are above (top), within (middle), and below (bottom) the zone of magnetic concentration decrease observed in Fig. 6.

\subsection{Hysteresis curves}

Typical hysteresis curves are presented in Fig. 7 after correcting the contribution of the paramagnetic component using high-field slopes, and all specimens were plotted on the so-called "Day plot" (Day et al., 1977) in Fig. 8; the ratio of saturation remanence to saturation magnetization $(\mathrm{Mrs} / \mathrm{Ms})$ versus the ratio of coercivity of remanence to coercivity $(\mathrm{Hcr} / \mathrm{Hc})$.

On the plot of $\mathrm{Mrs} / \mathrm{Ms}$ vs. $\mathrm{Hcr} / \mathrm{Hc}$, all data are within the pseudo-single-domain (PSD) region, but the position of each data point varies with depth in a systematic way (Fig. 8). The data points shallower than $1.2 \mathrm{~m}$ make a cluster at approxi- 


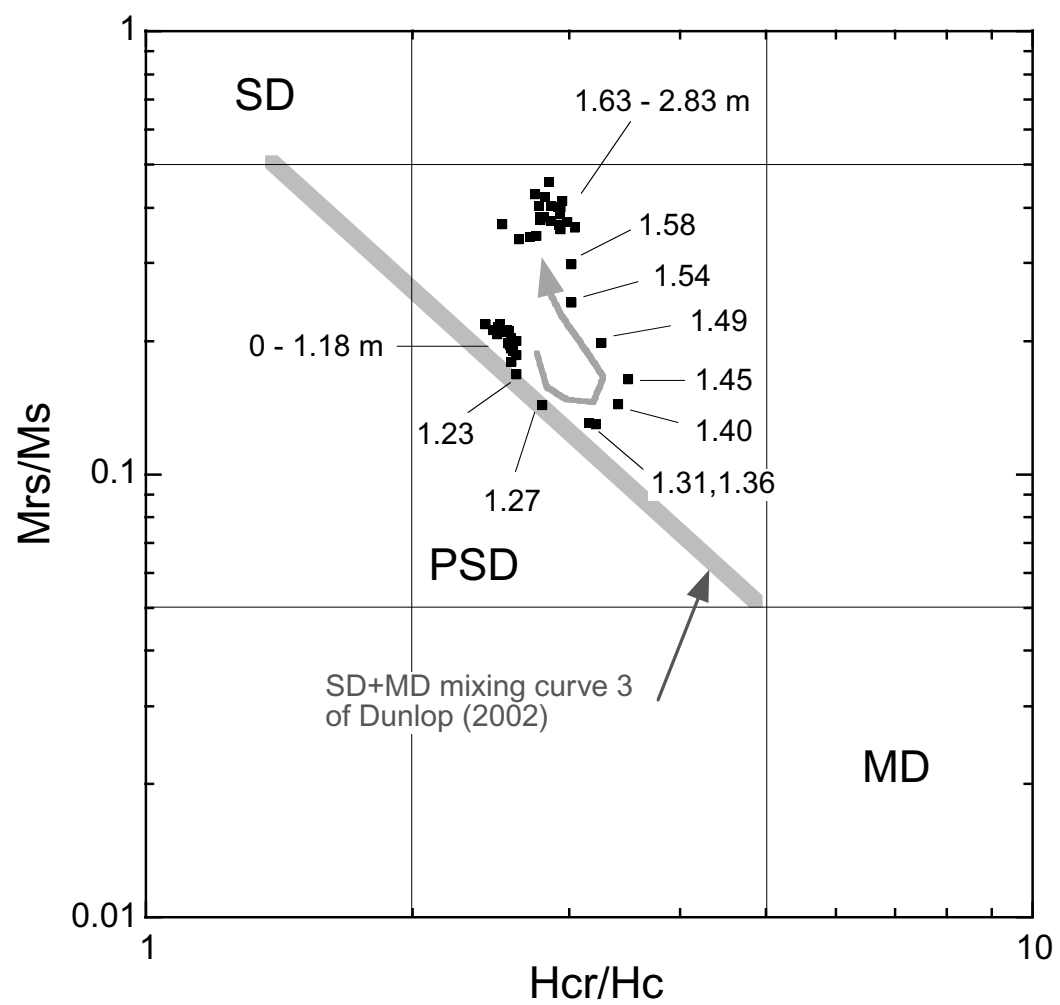

Fig. 8. Down-core variation of hysteresis parameters. Ratio of coercivity of remanence $(\mathrm{Hcr})$ to coercivity $(\mathrm{Hc})$ vs. ratio of saturation remanence $(\mathrm{Mrs})$ to saturation magnetization $(M s)$. Thick gray line represents theoretical variation trend for mixture of single-domain (SD) and multi-domain (MD) grains after Curve 3 of Dunlop (2002).

(a)

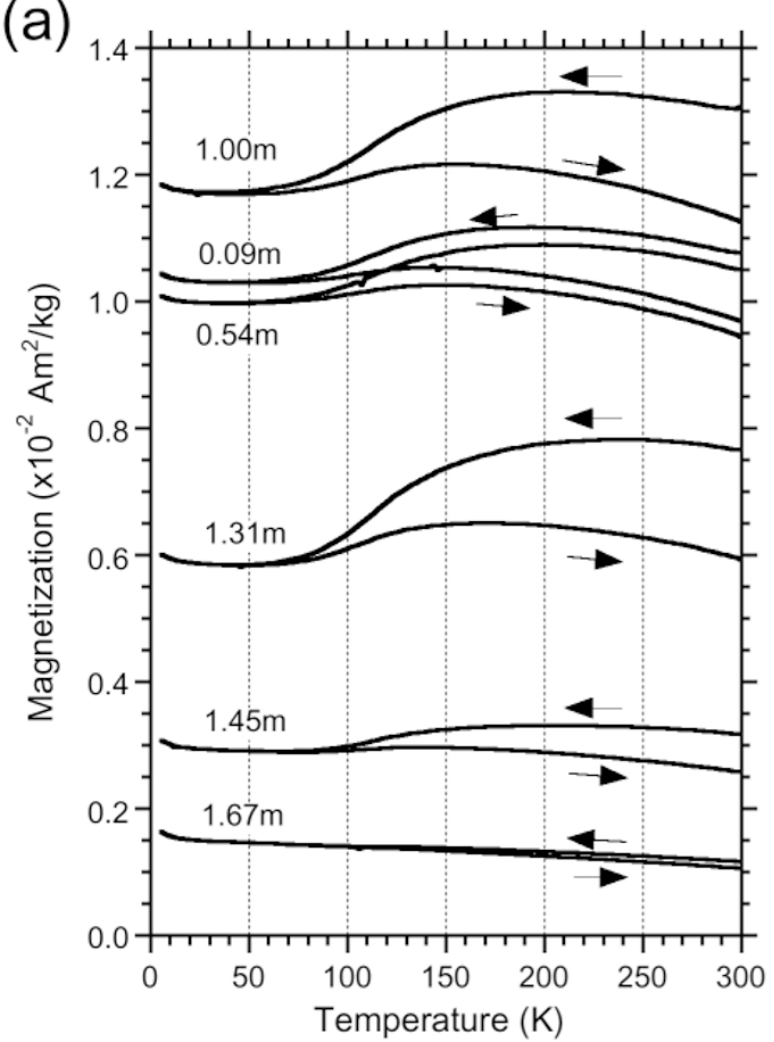

(b)

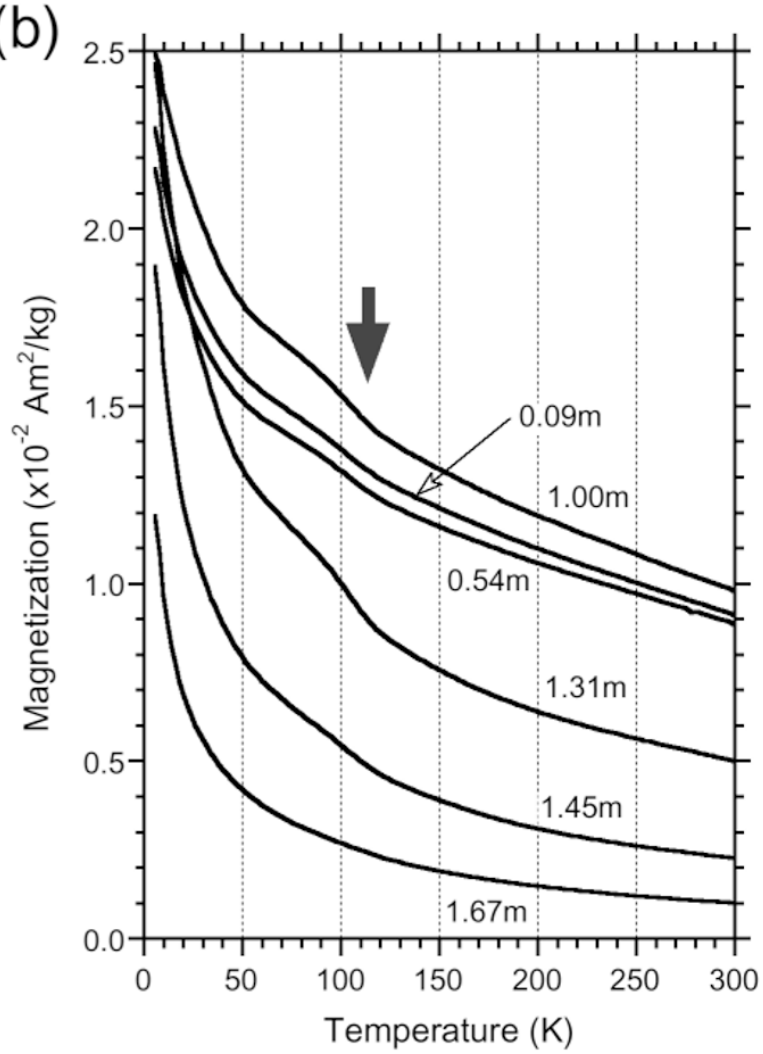

Fig. 9. Examples of low-temperature magnetometry data. (a) Low-temperature cycling of SIRM acquired at $300 \mathrm{~K}$. (b) Thermal decay of SIRM acquired at $6 \mathrm{~K}$. Signs of the occurrence of magnetite, which are differences of the magnetization during cooling and warming above about $100 \mathrm{~K}$ (a) and increases of the slopes at about $120 \mathrm{~K}$ during thermal decay indicated by an arrow in (b), are more obvious between about 1.0 and $1.4 \mathrm{~m}$, which is a little shallower than the zone of magnetic concentration decrease. 
(a)

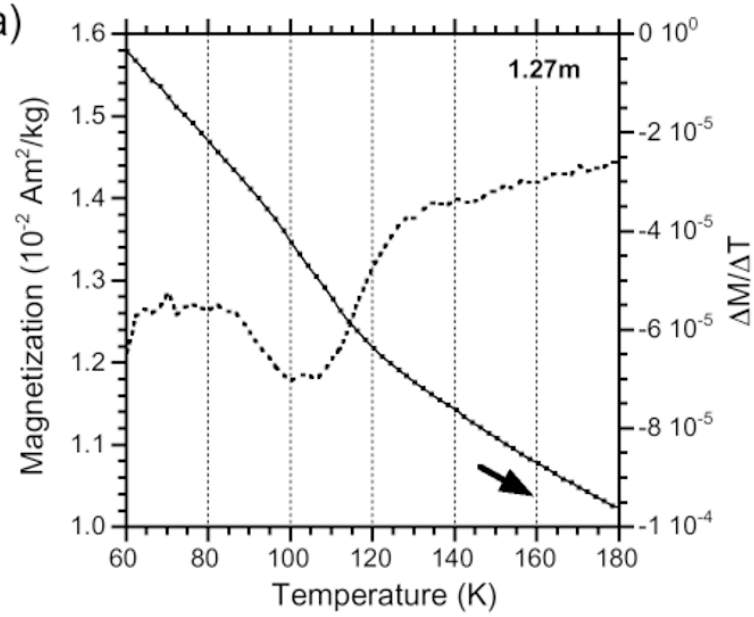

(c)

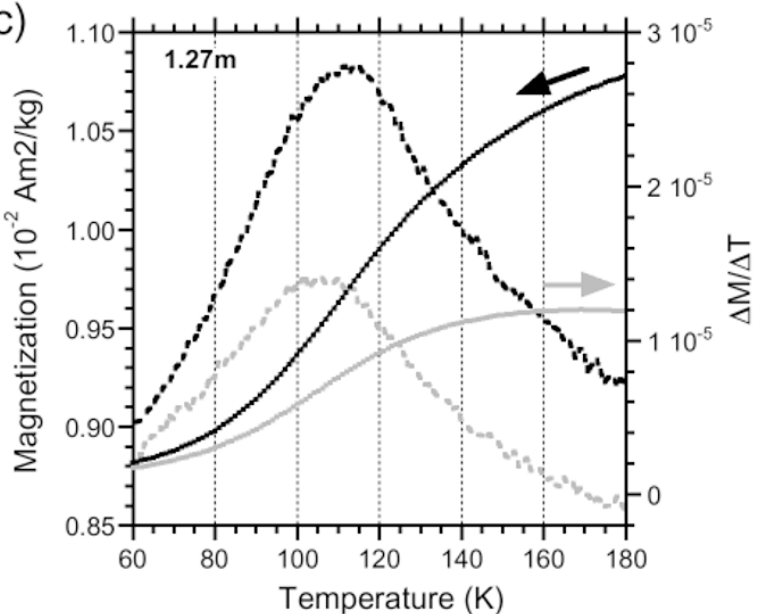

(b)

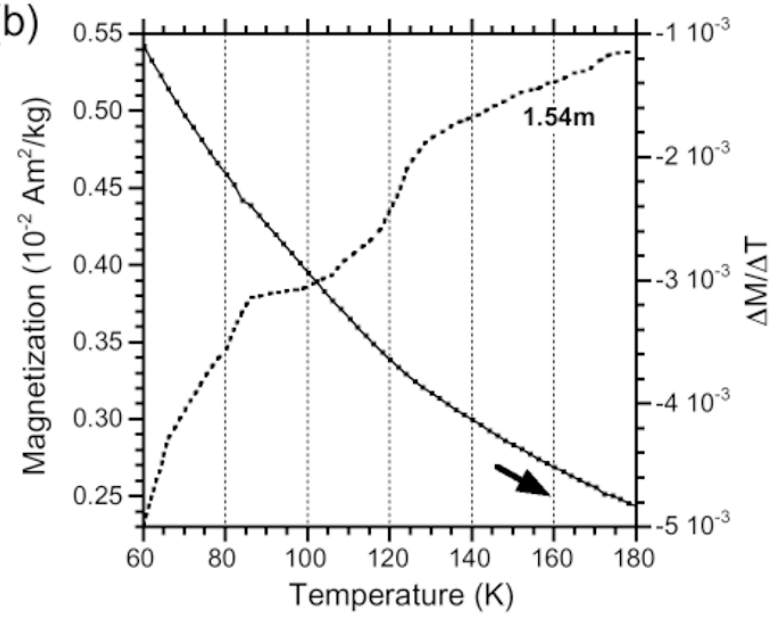

(d)

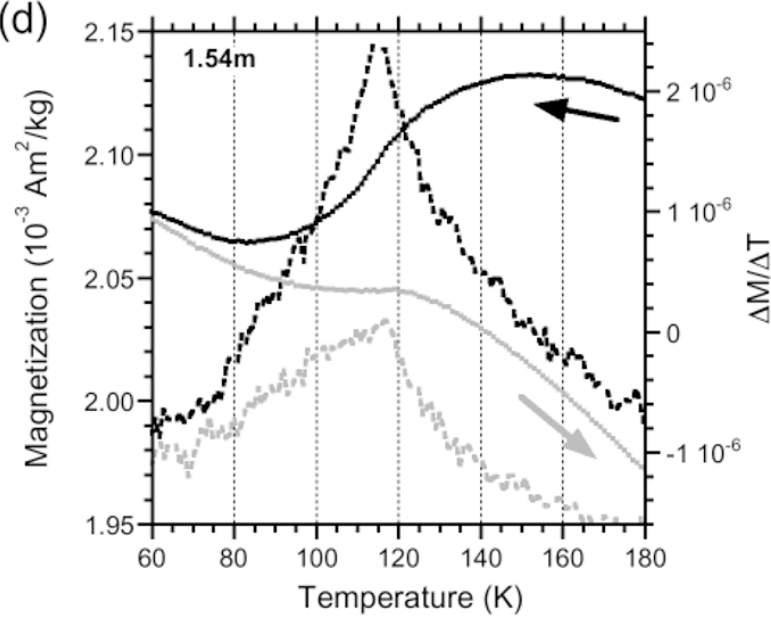

Fig. 10. (a) (b) Thermal decay of $6 \mathrm{~K}$ SIRM (solid curves) enlarged for a temperature range from 60 to $180 \mathrm{~K}$. Derivatives $(\Delta M / \Delta T)$ are indicated by broken curves. (c) (d) Loss and partial recovery of magnetization around $120 \mathrm{~K}$ during low-temperature cycling of $300 \mathrm{~K}$ SIRM (solid curves) and their derivatives (broken curves, black: cooling, gray: warming). Note that changes of magnetization are sharper (narrower peaks in $\Delta M / \Delta T$ curves) below the zone of magnetic concentration decrease (d) than above it (c).

mately $\mathrm{Mrs} / \mathrm{Ms}=0.2$ and $\mathrm{Hcr} / \mathrm{Hc}=2.5$, which is close to the mixing line of single-domain (SD) and multi-domain (MD) grains derived theoretically by Dunlop (2002). Between 1.23 and $1.36 \mathrm{~m}$, they move toward the MD region as depths increase, which suggests an increase of magnetic grain size in average. In accordance with the coarsening, the hysteresis curves become thinner (Fig. 7). Then, the data leave the mixing line and move upward in the PSD box with increasing depths between 1.4 and $1.6 \mathrm{~m}$. Finally they make a cluster again near $\mathrm{Mrs} / \mathrm{Ms}=0.4$ and $\mathrm{Hcr} / \mathrm{Hc}=2.8$ below $1.63 \mathrm{~m}$ (Fig. 8). The hysteresis curves of the deeper cluster show a wasp-waisted type (Fig. 7), suggesting that the magnetic grains in the sediments consist of a mixture of significantly different coercivity fractions (Roberts et al., 1995; Tauxe et al., 1996). The depth interval of the movement on the plot of $\mathrm{Mrs} / \mathrm{Ms}$ vs. $\mathrm{Hcr} / \mathrm{Hc}$ (1.2 to $1.6 \mathrm{~m}$ ) corresponds to the depths from the start of the decrease in ARM to the end of the decrease in $k$ (Fig. 6(a)).

\subsection{Low-T magnetometry}

Low-temperature magnetometry indicates the occurrence of magnetite throughout the sediment core. Magnetization during cooling down was larger than during warming up above about $100 \mathrm{~K}$ (Fig. 9(a)). The loss of remanent magnetization during the low-temperature cycle is most likely caused by passing through the magnetic isotropic point of magnetite $\left(\mathrm{T}_{\mathrm{I}}\right)$ and the Verwey transition. The temperature of $\mathrm{T}_{\mathrm{I}}$ is at about $130 \mathrm{~K}$ for pure magnetite, and lowered by substitution of $\mathrm{Ti}^{4+}$ (Dunlop and Özdemir, 1997). The Verwey transition is a crystallographic phase transition known to occur at 110-120 K for pure magnetite (Verwey, 1939), and lowered and obscured by oxidization (maghemitization) and Ti substitution (Özdemir and Dunlop, 1993; Honig, 1995). Another sign of the presence of magnetite is a slight increase of the slope of the thermal demagnetization curves around $110 \mathrm{~K}$ (Fig. 9(b)). This could be a manifestation of the Verwey transition. Pyrrhotite is considered to be absent because the magnetic transition at 30 to $34 \mathrm{~K}$ indicative of pyrrhotite (Rochette et al., 1990) was not observed.

The sign of the presence of magnetite is more obvious in a depth interval from about 1.0 to $1.4 \mathrm{~m}$. In the examples of Fig. 9, the difference of magnetization during cooling and warming above ca. $100 \mathrm{~K}$ is larger on the samples from $1.00 \mathrm{~m}$ and $1.31 \mathrm{~m}$ in depth than others, and the increase of the slope around $110 \mathrm{~K}$ during thermal decay is also larger 


\section{MaxSlope Temperature (K)}

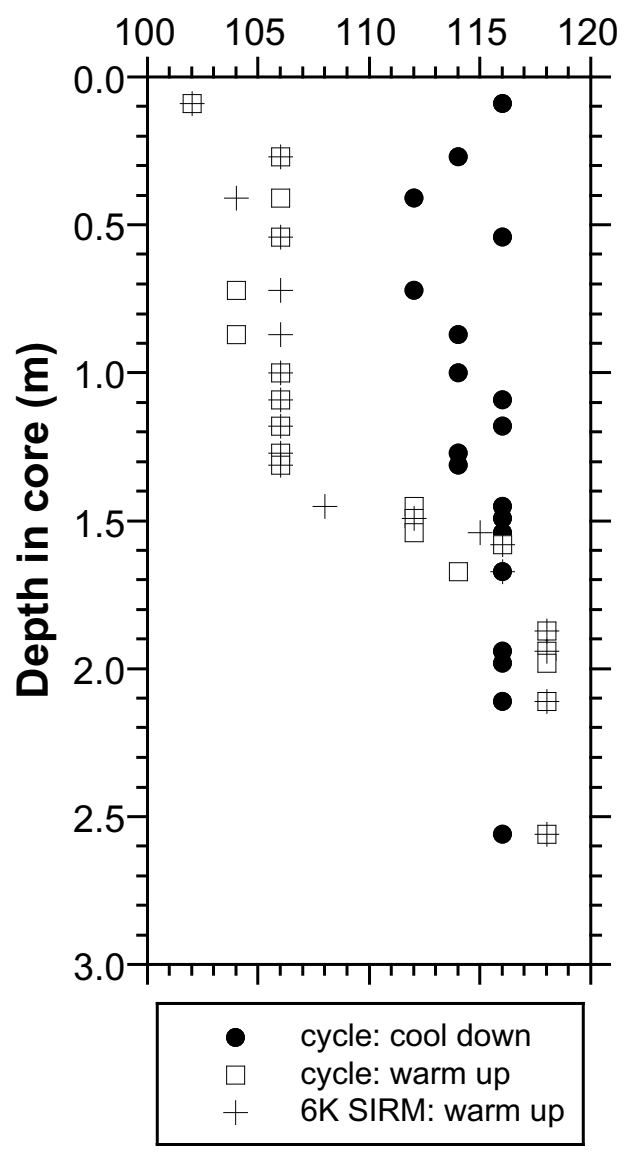

Fig. 11. Downcore variations in temperature of magnetization change (maximum slope in Fig. 10). Near the bottom of the zone of magnetic concentration decrease at about $1.5 \mathrm{~m}$, the temperature of partial recovery of magnetization during warm up (open squares) increases from about 105 to $120 \mathrm{~K}$. Thermal decay curve shows a similar increase in the transition temperature (pluses). Temperature of the loss of magnetization during cooling down (solid squares) does not show significant variation.

on the two samples than others. Below about $1.4 \mathrm{~m}$, reduced remanent magnetization intensity due to the magnetic concentration decrease caused apparently small changes associated with the Verwey transition. The depth from which the Verwey transition becomes clearer (about $1.0 \mathrm{~m}$ ) is a little shallower than the beginning of the magnetic concentration decrease $(1.2 \mathrm{~m})$.

On a closer look of the thermal decay curves, we can recognize that the temperature of the Verwey transition slightly varies with depth, which is detected as differences in the temperature of the minimum of the derivative curve $(\Delta M / \Delta T)$ (Figs. 10(a) and (b)). The temperature is 115 to $120 \mathrm{~K}$ below $1.5 \mathrm{~m}$ in depth, whereas it is about $105 \mathrm{~K}$ above $1.35 \mathrm{~m}$ (Fig. 11). The temperature of $120 \mathrm{~K}$ is known as that of the Verwey transition of pure magnetite. These observations suggest reduction of maghemite to pure magnetite in the zone of the concentration decrease. Another intriguing change with depth was observed on the low-temperature cycling of $300 \mathrm{~K}$ SIRM. On the loss and partial recovery of magnetization around $120 \mathrm{~K}$, the changes of the magnetization are sharper below the zone of magnetic concentration decrease than above it (Figs. 10(c) and 10(d)), which is indicated by a narrower width and a sharper peak in derivative $(\Delta M / \Delta T)$ curves. The temperature of magnetization recovery (maximum in derivative) increases with depth from about 105 to $120 \mathrm{~K}$, whereas that of magnetization loss is about $115 \mathrm{~K}$ and does not vary significantly with depth (Fig. 11).

\section{Discussion}

\subsection{Rock magnetic changes with reduction diagenesis}

The magnetic properties of Core GH98-1232 show that the remanent magnetization is dominantly carried by magnetite throughout the core, which is evidenced by the occurrence of the Verwey transition in the low-T magnetometry and high $\mathrm{S}$ ratios. A high-coercivity component is also present, which is estimated to be carried by hematite although it has not been positively identified. Hematite can be transported to the coring site as eolian dust from the Asian continent and detritals mainly from Hokkaido, Japan.

We have presented downcore variations in magnetic properties: concentration and grain-size proxies, hysteresis curves, and the results of low-T magnetometry. The rapid downcore changes in magnetic properties between 1.2 and $1.6 \mathrm{~m}$ in depth can be explained by selective dissolution of magnetite with reduction diagenesis (e.g., Karlin, 1990; Bloemendal et al., 1993). The start of the magnetic property changes at $1.2 \mathrm{~m}$ in depth (about $5 \mathrm{ka}$ in age) coincide with the beginning of the downward increase of organiccarbon and total-sulfur contents, but not at the present Feredox boundary. The decrease of the magnetic concentration proxies in order of ARM, SIRM, and $k$ is consistent with the dissolution model because finer magnetic grains are expected to be dissolved earlier than larger grains due to the larger ratio of surface area to volume. Loss of finer magnetite grains at first explains the coarsening of magnetic grain size on the Day plot, thinner hysteresis curves, and the decreases in $k_{\mathrm{ARM}} / k$ and SIRM $/ k$ at depths between 1.20 to $1.35 \mathrm{~m}$. Then, dissolution of even larger magnetite grains causes a relative increase of the contribution of hematite, which results in the deviation from the SD-MD mixing trend on the Day plot, the wasp-wasted hysteresis curves, and the decreases of $\mathrm{S}$ ratios. The gradual downcore grain-size increase between 0.7 and $1.2 \mathrm{~m}$ may be due to a slow dissolution of fine grains precursory of the rapid loss, or a change in magnetic mineral supply. In the low-T magnetometry, the appearance of the Verwey transition becomes clearer at about $1.0 \mathrm{~m}$, a little shallower than the depth of the rapid dissolution. We interpret the observation that surface of magnetites was oxidized to maghemite probably before transportation to the seafloor, and remained oxidized above about $1.0 \mathrm{~m}$. During the reduction diagenesis, the maghemite skin is first reduced to pure magnetite and then the grain is dissolved. The same phenomenon was already reported by Torii (1997) in the sediments from the Mediterranean Sea. The observations that the phase transition becomes sharper and its temperature rises to about $120 \mathrm{~K}$ below the zone suggest that the composition of magnetic minerals becomes closer to pure magnetite. This also supports the occurrence of maghemite-to-magnetite reduction.

The relative increase in the contribution of high-coercivity minerals in the zone of dissolution suggests that hematite 
could be more resistive to reduction diagenesis (Sahota et al., 1995; Robinson et al., 2000; Nowaczyk et al., 2002). Another possibility is that the average grain size of magnetites is smaller than hematites, and thus loss of finer fractions caused an increase of relative abundance of hematites. The magnetite assemblage would contain ultrafine biogenic grains, which were reported from Japan Sea sediments (Akai et al., 1991), whereas hematites consist of only detrital origin. The upper limit of the SD-size range of hematite, $\sim 0.015 \mathrm{~mm}$ (Banerjee, 1971), is much larger than that of magnetite, which may also cause the relative increase of remanent magnetization carried by hematite by loss of finer fractions. Passier et al. (2001) documented an increase of coercivity during reduction diagenesis in the sapropel $\mathrm{S} 1$ in the Mediterranean Sea. They explained it by partial maghemitization, as $\mathrm{Fe}^{2+}$ is more easily detached from the mineral structure than $\mathrm{Fe}^{3+}$. In our core, however, the results of low-temperature magnetometry suggest the occurrence of maghemite-to-magnetite reduction.

Synchronous decrease of magnetic concentration and S ratio has often been documented in studies on environmental magnetism, and many were interpreted as selective dissolution of (titano-) magnetites on reduction diagenesis (Sahota et al., 1995; Eriksson and Sandgren, 1999; Stockhausen and Thouveny, 1999; Vigliotti et al., 1999; Nowaczyk et al., 2002). For example, Nowaczyk et al. (2002) documented that zones of low magnetic concentrations coincide with those of low $\mathrm{S}$ ratios and high organic carbon content in anoxic lake sediments from Siberia. Lower $\mathrm{S}$ ratios are associated with higher $\mathrm{Mrs} / \mathrm{Ms}$ ratios but similar $\mathrm{Hcr} / \mathrm{Hc}$ ratios in magnetic hysteresis, which is similar to our observation. They considered that magnetite was dissolved whereas hematite could persist under anoxic conditions. Some studies, on the other hand, interpreted the correlation of magnetic concentration and $\mathrm{S}$ ratio in a different way: changes in supply of magnetic minerals. Vigliotti (1997) studied rock-magnetic changes accompanied by glacial-interglacial cycles in Japan Sea sediments cored by ODP Leg 127 . He reported lows in both magnetic concentration and $\mathrm{S}$ ratio in glacial, relatively anoxic sediments, and estimated that $\mathrm{S}$ ratio represents eolian input. Ishikawa and Frost (2002) reported zones of low magnetic concentration with relatively high abundance of high-coercivity minerals (lower S ratios) in sediments of several hundred meters below the seafloor of the Woodlark Basin cored by ODP Leg 180. Magnetic hysteresis data from the low concentration zones showed higher $\mathrm{Mrs} / \mathrm{Ms}$ ratios but similar $\mathrm{Hcr} / \mathrm{Hc}$ ratios compared with the sediments with higher magnetic concentration, which is similar to our study. They favored an interpretation related to changes of a depositional environment controlled by tectonics. In interpreting decreases of $\mathrm{S}$ ratio, we suggest that it would be important to examine possible occurrence of reductive dissolution as well as changes of magnetic mineral supply.

There is no evidence for production of new magnetic phases with reduction diagenesis in our sediment core. Pyrrhotite was not detected by the low-temperature magnetometry, although Kobayashi and Nomura (1972) reported pyrrhotite from Japan Sea sediments. Their conclusion is mainly based on thermomagnetic analysis and X-ray diffrac- tion. Their thermomagnetic curves were interpreted as thermal inversion of sulfides to magnetites, but pyrrhotite was not positively identified. The X-ray diffraction showed that magnetite and pyrite were dominant iron oxides/sulfides, but the identification of pyrrhotite was not unequivocal. The different conclusion may also have arisen from the difference in coring sites. Their cores were taken from deeper parts of the Japan Sea, more than $3000 \mathrm{~m}$ in water depth, where oceanographic conditions may be different from our site. It is difficult to identify greigite by rock-magnetic technique: greigite does not show magnetic phase transition in low temperatures like magnetite and pyrrhotite (Roberts, 1995). Greigite is known to show great gyroremanent effect, and acquire large gyroremanent magnetization (GRM) during static AF demagnetization, which results in abnormal remanence directions above fields of $40 \mathrm{mT}$ or so (Snowball, 1997a; Hu et al., 1998; Sagnotti and Winkler, 1999). This phenomenon could be an empirical method for detecting greigite. In our sediments, no anomalous behavior was observed during static AF demagnetization, even at the horizon of the maximum total-sulfur content (Figs. 2 and 4). Large spikes in SIRM/k have been often reported in association with the preservation of greigite (e.g. Roberts et al., 1996; Snowball, 1997b), but this was not observed here (Fig. 6(b)).

Precipitation of authigenic and/or biogenic magnetites can occur just above the Fe-redox boundary which corresponds to a tan-green color change of sediments (Karlin et al., 1987; Tarduno and Wilkison, 1996). In our sediment core, little surface oxidized layer was observed (ca. $0.02 \mathrm{~m}$ ), and the Fe-redox boundary is estimated to be very close to the sediment-water interface. The precipitation of magnetites hence should take place very close to the sediment-water interface, if it occurs, and its timing of remanent magnetization acquisition would not differ significantly from primary depositional remanent magnetization (DRM).

The higher contents of organic carbon and total sulfur between 2.0 and $1.3 \mathrm{~m}$, which probably caused the magneticmineral dissolution, indicate higher biological productivity in this interval. Its age, from about 10 to $5 \mathrm{ka}$, corresponds to some paleoceanographic events such as an inflow of the Tsushima warm current from the Tsushima Strait (the southwestern end of the Japan Sea) since $10 \mathrm{ka}$ and the postglacial sea-level rise, which reached to the highest level at about $6 \mathrm{ka}$ around Japan. The occurrence of the dissolution zone may hence be an indicator of such paleoenvironmental changes in the Japan Sea. However, biological and geochemical responses to a paleoceanographic event may not be similar among different surface and deep water masses in the Japan Sea, and hence rock-magnetic studies of sediment cores from different water depths as well as other areas are required for establishing paleoenvironmental interpretation of the magnetic dissolution zone. This also applies to the magnetic-property variations corresponding to the TL layers.

\subsection{Secular variation in inclination}

Although Core GH98-1232 has suffered from dissolution of magnetite during reduction diagenesis, information on paleomagnetic directions is expected to have been preserved because there is no evidence for precipitation of secondary magnetic phases. Selective dissolution of finer magnetic grains caused the decrease of the coercivity of remanent 

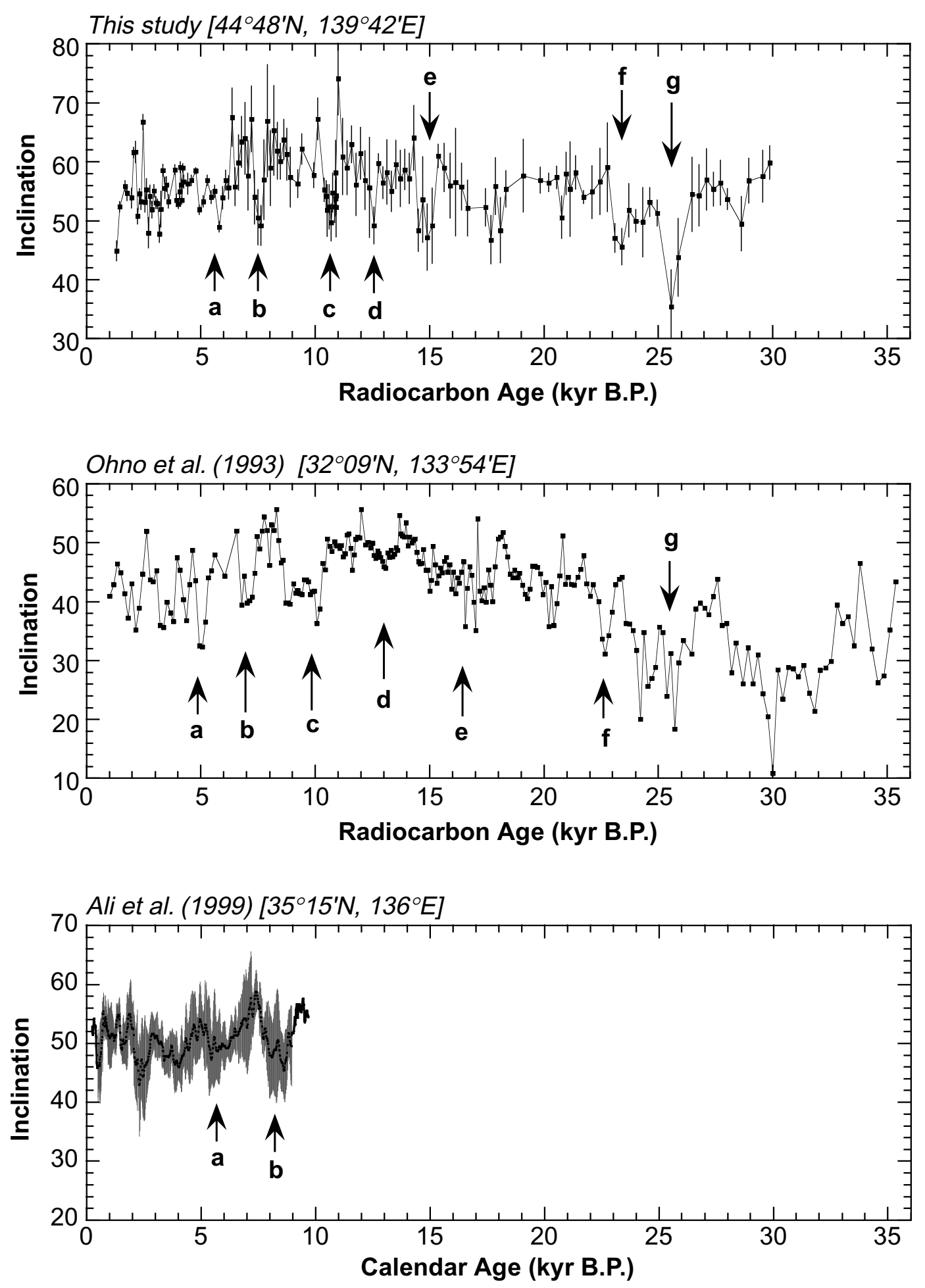

Fig. 12. Correlation of inclination variations of Core GH98-1232 with the record of a sediment core off southwest Japan (Ohno et al., 1993) and the stacked record of three cores from the Lake Biwa (Ali et al., 1999). Note the difference of time scale: radiocarbon ages (Ohno et al., 1993, and this study) and calendar age (Ali et al., 1999).

magnetization within and below the dissolution zone (Fig. 4), but the stepwise AF demagnetization experiment showed that the samples have relatively stable remanent magnetization with little magnetic overprint. These observations make it possible to discuss secular variations.

Holocene secular variations have been intensively studied, and a master curve was proposed for the southwest Japan (Hyodo et al., 1993). However, high-resolution records of older than $10 \mathrm{ka}$ are still scarce. The record of Ohno et al. (1993) from a sediment core off southwest Japan, which covers the last $35 \mathrm{kyrs}$, is the only well-dated, published record around Japan within the knowledge of the authors. Inclination variations of Ohno et al. (1993) and ours resemble well each other (Fig. 12): the inclination lows indicated by arrows in the figure appear commonly within uncertainty of the age. Please note that the carbon reservoir effect of 400 years 
was applied to the ${ }^{14} \mathrm{C}$ ages of Ohno et al. (1993), but not for our record. Better agreement would be derived if the ages of Ohno et al. (1993) between 15 and $20 \mathrm{ka}$ are shifted about 2 ka younger: their record has few control points in age around $15 \mathrm{ka}$. At about $30 \mathrm{ka}$, very shallow inclination was observed only in Ohno et al. (1993), but the ages of our record older than $\sim 24$ ka were not constrained well. The low inclinations observed in both records at about $25 \mathrm{ka}$ are close in age to the Mono Lake excursion (e.g. 27-25.5 ka, Nowaczyk and Knies, 2000), although its existence is still a matter of debate (Kent et al., 2002). The two records also show a similar long-term trend. Inclinations are relatively steep around 6-14 ka, and decrease with increasing age. Concerning the variations during the last $10 \mathrm{kyr}$, lows at about 5 and $8 \mathrm{ka}$ are commonly observed among available records in Japan (Yamazaki et al., 1985; Hyodo et al., 1993; Ali et al., 1999), although resolution of our core is relatively low because of slow sedimentation. Please note the difference in the time scales of Fig. 12. Our record and that of Ohno et al. (1993) are based on ${ }^{14} \mathrm{C}$ ages, but the stacked record of Ali et al. (1999) from cores of the Lake Biwa was controlled by calendar ages of two volcanic ash layers. They adopted the calendar age of $7250 \mathrm{yr}$ B.P. for the Kikai-Akahoya (K-Ah) ash, which corresponds to ${ }^{14} \mathrm{C}$ age of $6300 \mathrm{yr}$ B.P. The agreement of inclination variations of Core GH98-1232 with published records indicates that they represent behavior of the geomagnetic field, and that anoxic sediments can be used for paleomagnetic studies after careful rock-magnetic examination, as suggested by Yamazaki and Oda (2001).

The mean inclination of our sediment core during the last 20 kyrs (data older than 20 ka were not used to avoid any bias of possible excursion at about $25 \mathrm{ka}$ ) is about $56^{\circ}$, and the underestimation caused by averaging inclination-only data is estimated to be about $1^{\circ}$ for the site latitude (McFadden and Reid, 1982; Cox and Gordon, 1984). The corrected mean inclination, about $57^{\circ}$, is somewhat shallower than that expected from the geocentric axial dipole (GAD) at the site, $63^{\circ}$, but fairly close to the recent geomagnetic field, $59^{\circ}$, based on the International Geomagnetic Reference Field 2000. The record of Ohno et al. (1993) during the last 20 kyrs also shows the corrected mean inclination about $6^{\circ}$ shallower than expected from GAD, which is similar magnitude to our core. This suggests that a non-dipole component may have persisted during the last $\sim 20$ kyrs around Japan.

\section{Conclusions}

Our study on rock-magnetism and paleomagnetism of Core GH98-1232 taken from the northeastern part of the Japan Sea revealed followings.

(1) Dissolution of magnetic minerals occurs between 1.2 and $1.6 \mathrm{~m}$ in depth of the core (about 5-8 ka in age). Finer magnetic grains were lost earlier than larger grains. The start of the dissolution is synchronous with increases in organiccarbon and total-surfer contents, but this horizon does not coincide with the present Fe-redox boundary, which is at about $0.02 \mathrm{~m}$ below the sediment-water interface.

(2) The dominant carrier of the remanent magnetization is magnetite throughout the core. Relative contribution of high-coercivity magnetic minerals like hematite increases as the dissolution proceeds. Hematite is estimated to be more resistive to the reductive dissolution than magnetite.

(3) From low-temperature magnetometry, it is estimated that magnetites with maghemite were reduced to pure magnetites, which starts at about $1.0 \mathrm{~m}$, a little shallower than the dissolution zone.

(4) There is no evidence for precipitation of secondary magnetic phases associated with the reduction diagenesis. Neither pyrrhotite nor greigite was detected. This suggests the possibility that information on paleomagnetic directions has been preserved even after the reduction diagenesis.

(5) Primary sedimentary magnetic fabric has been preserved in most part of the core. NRM consists of single magnetization component, and MADs on PCA are $1-3^{\circ}$ and about $5^{\circ}$ above and below the dissolution zone, respectively.

(6) Inclination variations during the last $30 \mathrm{kyrs}$ recorded in our core resemble closely to the secular variation records available around Japan, in particular the record of Ohno et al. (1993). This suggests that anoxic sediments could be used for reconstructing geomagnetic-field behavior in the past after careful rock-magnetic examination.

Acknowledgments. The core was obtained with the cooperation of all onboard scientists, officers and crew of the GH98 cruise of $\mathrm{R} / \mathrm{V}$ Hakurei-maru. Part of this work was done when A.A. stayed in GSJ and Tsukuba University as an STA Fellow and a JSPS Fellow, and we thank Yujiro Ogawa and Eiichi Kikawa for their support. Thanks are also extended to Naoto Ishikawa for allowing the measurements on the MicroMag and to Hirokuni Oda, Yuhji Yamamoto, and reviewers, Chorng-Shern Horng and Akira Hayashida, for careful reading of the manuscript.

\section{References}

Akai, J., T. Sato, and S. Okusa, TEM study on biogenic magnetite in deepsea sediments from the Japan Sea and the Western Pacific Ocean, $J$ Electron Microsc., 40, 110-117, 1991.

Ali, M., H. Oda, A. Hayashida, K. Takemura, and M. Torii, Holocene palaeomagnetic secular variation at Lake Biwa, central Japan, Geophys. J. Int., 136, 218-228, 1999.

Banerjee, S. K., New grain size limits for palaeomagnetic stability in haematite, Nature Phys. Sci., 232, 15-16, 1971.

Bloemendal, J., J. W. King, F. R. Hall, and S.-J. Doh, Rock magnetism of Late Neogene and Pleistocene deep-sea sediments: relationship to sediment source, diagenetic processes, and sediment lithology, J. Geophys. Res., 97, 4361-4375, 1992

Bloemendal, J., J. W. King, A. Hunt, P. B. Demenocal, and A. Hayashida, Origin of the sedimentary magnetic record at Ocean Drilling Program Sites on the Owen Ridge, Western Arabian Sea, J. Geophys. Res., 98, 4199-4219, 1993.

Channell, J. E. T. and B. Lehman, The last two geomagnetic polarity reversals recorded in high-deposition-rate sediment drifts, Nature, 389, 712$715,1997$.

Cox, A. and R. G. Gordon, Paleolatitudes determined from paleomagnetic data from vertical cores, Rev. Geophys. Space Phys., 22, 47-72, 1984.

Day, R., M. Fuller, and V. A. Schmidt, Hysteresis properties of titanomagnetites: grain-size and compositional dependence, Phys. Earth Planet. Inter., 13, 260-267, 1977.

Dunlop, D. J., Theory and application of the Day plot $(\mathrm{Mrs} / \mathrm{Ms}$ versus $\mathrm{Hcr} / \mathrm{Hc}$ ) 1. Theoretical curves and tests using titanomagnetite data, $J$ Geophys. Res., 107, 10.1029/2001JB000486, 2002.

Dunlop, D. J. and Ö. Özdemir, Rock Magnetism: Fundamentals and Frontiers, 573 pp., Cambridge University Press, Cambridge, 1997.

Eriksson, M. G. and P. Sandgren, Mineral magnetic analysis of sediment cores recording recent soil erosion history in central Tanzania, Paleogeogr. Paleoclimatol. Paleoecol., 152, 365-383, 1999.

Honig, J. M., Analysis of the Verwey transition in magnetite, J. Alloys Compounds, 229, 24-39, 1995.

Hu, S., E. Appel, V. Hoffmann, W. W. Schmahl, and S. Wang, Gyromagnetic remanence acquired by greigite $\left(\mathrm{Fe}_{3} \mathrm{~S}_{4}\right)$ during static three-axis alternat- 
ing field demagnetization, Geophys. J. Int., 134, 831-842, 1998.

Hyodo, M., C. Itota, and K. Yaskawa, Geomagnetic secular variation reconstructed from magnetizations of wide-diameter cores of Holocene sediments in Japan, J. Geomag. Geoelectr., 45, 669-696, 1993.

Ikehara, K., K. Kikkawa, H. Katayama, and K. Seto, Late Quaternary paleoceanography of the Japan Sea: a tephrochronological and sedimentological study, in Proc. 29th Int'l. Geol. Congr., Pt. B, edited by R. G. Coleman and E. H. Juvigne, pp. 229-235, VSP, Utrecht, 1994.

Ikehara, K., H. Katayama, and T. Nakajima, AMS ${ }^{14} \mathrm{C}$ ages of cored material collected from central to southeastern Japan Sea, Bull. Geol. Surv. Japan, 47, 309-316, 1996 (in Japanese with English abstract).

Ishikawa, N. and G. M. Frost, Magnetic properties of sediments from Ocean Drilling Program sites 1109, 1115, and 1118 (Leg 180), Woodlark Basin (Papua New Guinea), Earth Planets Space, 54, 883-897, 2002.

Itaki, T. and K. Ikehara, Radiolarian biozonation for the upper Quaternary in the Japan Sea, J. Geol. Soc. Japan, 109, 96-105, 2003.

Karlin, R., Magnetite diagenesis in marine sediments from the Oregon continental margin, J. Geophys. Res., 95, 4405-4419, 1990

Karlin, R., M. Lyle, and G. R. Heath, Authigenic magnetite formation in suboxic marine sediments, Nature, 326, 490-493, 1987.

Kent, D. V., S. R. Hemming, and B. D. Turrin, Laschamp excursion at Mono Lake?, Earth Planet. Sci. Lett., 197, 151-164, 2002.

Kirschvink, J. L., The least-squares line and plane and the analysis of paleomagnetic data, Geophys. J. R. astr. Soc., 62, 699-718, 1980.

Kobayashi, K. and M. Nomura, Iron sulfides in the sediment cores from the Sea of Japan and their geophysical implications, Earth Planet. Sci. Lett., 16, 200-208, 1972.

Maher, B. A. and R. Thompson (eds.), Quaternary Climates, Environments and Magnetism, 390 pp., Cambridge University Press, Cambridge, 1999.

McFadden, P. L. and A. B. Reid, Analysis of palaeomagnetic inclination data, Geophys. J. R. astr. Soc., 69, 307-319, 1982

Nowaczyk, N. R. and J. Knies, Magnetostratigraphic results from the eastern Arctic Ocean: AMS ${ }^{14} \mathrm{C}$ ages and relative paleointensity data of the Mono Lake and Laschamp geomagnetic reversal excursions, Geophys. J. Int., 140, 185-197, 2000.

Nowaczyk, N. R., P. Minyuk, M. Melles, J. Brigham-Grette, O. Glushkova, M. Nolan, A. V. Lozhkin, T. V. Stetsenko, P. M. Andersen, and S. L. Forman, Magnetostratigraphic results from impact crater Lake El'gygytgyn, northeastern Siberia: a 300 kyr long high-resolution terrestrial palaeoclimatic record from the Arctic, Geophys. J. Int., 150, 109-126, 2002.

Oba, T., M. Kato, H. Kitazato, I. Koizumi, A. Omura, T. Sakai, and T. Takayama, Paleoenvironmental changes in the Japan Sea during the last 85,000 years, Paleoceanography, 6, 499-518, 1991.

Oba, T., M. Maruyama, E. Matsumoto, and T. Nakamura, AMS- ${ }^{14} \mathrm{C}$ ages of Japan Sea cores from the Oki Ridge, The Quat. Res., 34, 289-296, 1995 (in Japanese with English abstract)

Ohno, M., Y. Hamano, M. Maruyama, E. Matsumoto, H. Iwakura, T. Nakamura, and A. Taira, Paleomagnetic record over the past 35,000 years of a sediment core from off Shikoku, southwest Japan, Geophys. Res. Lett. 20, 1395-1398, 1993.

Özdemir, Ö and D. J. Dunlop, The effect of oxidation on the Verwey transition in magnetite, Geophys. Res. Lett., 20, 1671-1674, 1993.

Passier, H. F., G. J. de Lange, and M. J. Dekkers, Magnetic properties and geochemistry of the active oxidation front and the youngest sapropel in the eastern Mediterranean Sea, Geophys. J. Int., 145, 604-614, 2001.

Roberts, A. P., Magnetic properties of sedimentary greigite $\left(\mathrm{Fe}_{3} \mathrm{~S}_{4}\right)$, Earth Planet. Sci. Lett., 134, 227-236, 1995.

Roberts, A. P., Y. Cui, and K. L. Verosub, Wasp-waisted hysteresis loops: Mineral magnetic characteristics and discrimination of components in mixed magnetic systems, J. Geophys. Res., 100, 17909-17924, 1995.

Roberts, A. P., R. L. Reynolds, K. L. Verosub, and D. P. Adam, Environmental magnetic implications of greigite $\left(\mathrm{Fe}_{3} \mathrm{~S}_{4}\right)$ formation in a $3 \mathrm{~m} . \mathrm{y}$. lake sediment record from Butte Valley, northern California, Geophys. Res. Lett., 23, 2859-2862, 1996.

Robinson, S. G., J. T. S. Sahota, and F. Oldfield, Early diagenesis in North Atlantic abyssal plain sediments characterized by rock-magnetic and geo- chemical indices, Mar. Geol., 163, 77-107, 2000.

Rochette, P., G. Fillion, J.-L. Mattei, and M. J. Dekkers, Magnetic transition at 30-34 Kelvin in pyrrhotite: insight into a widespread occurrence of this mineral in rocks, Earth Planet. Sci. Lett., 98, 319-328, 1990.

Sagnotti, L. and A. Winkler, Rock magnetism and palaeomagnetism of greigite-bearing mudstones in the Italian peninsula, Earth Planet. Sci. Lett., 165, 67-80, 1999.

Sahota, J. T. S., S. G. Robinson, and F. Oldfield, Magnetic measurements used to identify paleoxidation fronts in deep-sea sediments from the Madeira Abyssal Plain, Geophys. Res. Lett., 22, 1961-1964, 1995.

Snowball, I. F., The detection of single-domain greigite $\left(\mathrm{Fe}_{3} \mathrm{~S}_{4}\right)$ using rotational remanent magnetization (RRM) and the effective gyro field $(B g)$ : mineral magnetic and palaeomagnetic applications, Geophys. J. Int., 130, 704-716, 1997a.

Snowball, I. F., Gyroremanent magnetization and the magnetic properties of greigite-bearing clays in southern Sweden, Geophys. J. Int., 129, 624$636,1997 \mathrm{~b}$.

Stockhousen, H. and N. Thouveny, Rock-magnetic properties of Eemian maar lake sediments from Massif Central, France: a climatic signature?, Earth Planet. Sci. Lett., 173, 299-313, 1999.

Tada, R., I. Koizumi, A. Cramp, and A. Rahman, Correlation of dark and light layers, and the origin of their cyclicity in the Quaternary sediments from the Japan Sea, in Proc. ODP Sci. Results, 127/128, Pt.1, edited by K. A. Pisciotto, J. C. Ingle, Jr., M. T. von Breymann, and J. Barron, et al., pp. 577-601, Ocean Drilling Program, College Station, 1992.

Tada, R., T. Irino, and I. Koizumi, Land-ocean linkages over orbital and millennial timescales recorded in late Quaternary sediments of the Japan Sea, Paleoceanography, 14, 236-247, 1999.

Tarduno, J. A. and S. L. Wilkison, Non-steady state magnetic mineral reduction, chemical lock-in, and delayed remanence acquisition in pelagic sediments, Earth Planet. Sci. Lett., 144, 315-326, 1996.

Tarling, D. H. and F. Hrouda, The Magnetic Anisotropy of Rocks, 217 pp., Chapman \& Hall, London, 1993.

Tauxe, L., T. A. T. Mullender, and T. Pick, Potbellies, wasp-waists, and superparamagnetism in magnetic hysteresis, J. Geophys. Res., 101, 571$583,1996$.

Terashima, S., K. Ikehara, and H. Katayama, Carbon and sulfur contents of sediment cores in the western Hokkaido coastal area, in Preliminary reports on researches in the 1998 fiscal year: "Comprehensive study on environmental changes in the western Hokkaido coastal area" and "Study on evaluation of marine active faults", GSJ Interim Report no. MG/99/1, pp. 166-172, Geological Survey of Japan, 1999 (in Japanese).

Torii, M., Low-temperature oxidation and subsequent downcore dissolution of magnetite in deep-sea sediments, ODP Leg 161 (Western Mediterranean), J. Geomag. Geoelectr., 49, 1233-1245, 1997.

Verwey, E. J. W., Electronic conduction of magnetite $\left(\mathrm{Fe}_{3} \mathrm{O}_{4}\right)$ and its transition point at low temperature, Nature, 144, 327-328, 1939.

Vigliotti, L., Magnetic properties of light and dark sediment layers from the Japan Sea: Diagenetic and paleoclimatic implications, Quat. Sci. Rev., 16, 1093-1114, 1997.

Vigliotti, L., L. Capotondi, and M. Torii, Magnetic properties of sediments deposited in suboxic-anoxic environments: relationships with biological and geochemical proxies, in Paleomagnetism and Diagenesis in Sediments, edited by D. H. Tarling and P. Turner, Geol. Soc. Lond. Spec. Publ., 151, pp. 71-83, 1999.

Yamazaki, T. and H. Oda, A Brunhes-Matuyama polarity transition record from anoxic sediments in the South Atlantic (Ocean Drilling Program Hole 1082C), Earth Planets Space, 53, 817-827, 2001.

Yamazaki, T., M. Joshima, and Y. Saito, Geomagnetic inclination during last 9,000 years recorded in sediment cores from Lake Kasumigaura, Japan, J. Geomag. Geoelectr., 37, 215-221, 1985.

T. Yamazaki (e-mail: toshi-yamazaki@aist.go.jp), A. L. Abdeldayem, and K. Ikehara 